\title{
Optimal Contents of an Airway Equipment Bag: Results of an Institutional Survey
}

\author{
AUTHOR: Ken Walsh FCARCSI, Gordon Wong FANZCA.
}

AFFILIATION: Department of Anaesthesia, Hospital for Sick Children, Toronto, Ontario, M5S 2W9. E mail: kenwalsh@ireland.com

Introduction: In-hospital emergencies are common in our institution. In the first nine months of 2004 there were 58 emergency calls to the wards, in 42 of these cases positive pressure ventilation of the lungs was necessary. Previous studies suggest that crash carts designed to carry emergency airway equipment may not always be readily available or adequately stocked [1, 2]. In view of this, anesthesia residents and fellows in our institution, carry a portable airway equipment bag to all emergencies. We carried out a department wide survey in an attempt to optimize the equipment included.

Methods: A questionnaire was sent to all 42 staff, fellows and residents in anesthesia working in the Hospital for Sick Children in October 2004. 64 items for possible inclusion in the bag were included on the questionnaire. Any item approved by more than $75 \%$ of the respondents was to be included in the bag.

Results: The response rate was 50\%. Table 1 lists the 37 items gaining more than $75 \%$ approval. Three items, the laryngeal mask (LMA) size 1, gum elastic bougie and Ayre's T-piece received only 50-75\% approval, but were placed on the list of equipment by the trauma committee. All three items have been show to be useful in emergencies.

Discussion: We believe this reconstituted portable airway equipment bag now contains adequate equipment to deal with immediate airway management in emergency situations.

References.

[1] Brenner BE, Kauffmann J. response to cardiac arrests in a hospital setting: delays in ventilation. Resuscitation 1996; 31 (1): 17-23.

[2] King D, Davies KN, Copes CS, Silas JH. Survey of cardiac arrests and cardiac arrest trolleys in a district general hospital. Brit J Clin Pract 1994; 48(5): 248-50. 
Table 1: Items gaining more than $75 \%$ approval for inclusion in portable airway bag.

\begin{tabular}{|c|c|}
\hline Items to be included. & $\%$ approval \\
\hline Face mask. & \\
\hline 1 & $86 \%$ \\
\hline 2 & $95 \%$ \\
\hline 3 & $95 \%$ \\
\hline 4 & $90 \%$ \\
\hline 5 & $86 \%$ \\
\hline \multicolumn{2}{|l|}{ Guedal airway. } \\
\hline 3 & $81 \%$ \\
\hline 4 & $86 \%$ \\
\hline 5 & $95 \%$ \\
\hline 6 & $95 \%$ \\
\hline 7 & $100 \%$ \\
\hline 8 & $95 \%$ \\
\hline 9 & $81 \%$ \\
\hline Straight blade size 1 . & $95 \%$ \\
\hline Curved blade size 3 . & $90 \%$ \\
\hline \multicolumn{2}{|l|}{ Uncuffed endotracheal tubes. } \\
\hline 2.5 & $90 \%$ \\
\hline 3.0 & $90 \%$ \\
\hline 3.5 & $86 \%$ \\
\hline 4.0 & $86 \%$ \\
\hline 4.5 & $81 \%$ \\
\hline 5.0 & $76 \%$ \\
\hline 5.5 & $76 \%$ \\
\hline \multicolumn{2}{|l|}{$\underline{\text { Cuffed endotracheal tubes. }}$} \\
\hline$\overline{5.5}$ & $76 \%$ \\
\hline 6.0 & $90 \%$ \\
\hline 6.5 & $76 \%$ \\
\hline 7.0 & $86 \%$ \\
\hline \multicolumn{2}{|l|}{ Laryngeal mask. } \\
\hline 2 & $90 \%$ \\
\hline 3 & $95 \%$ \\
\hline 4 & $81 \%$ \\
\hline Stylet. & $90 \%$ \\
\hline Macgills forceps. & $76 \%$ \\
\hline \multicolumn{2}{|l|}{ Drugs. } \\
\hline Propofol. & $76 \%$ \\
\hline Suxamethonium. & $95 \%$ \\
\hline Atropine. & $95 \%$ \\
\hline Rocuronium. & $76 \%$ \\
\hline Ketamine. & $76 \%$ \\
\hline
\end{tabular}

